\title{
USO DE SMARTPHONES NA PRÁTICA EDUCATIVA: EXPERIÊNCIA E PROCESSO CRIATIVO
}

\author{
SMARTPHONES USE IN EDUCATIONAL PRACTICE: \\ EXPERIENCE AND CREATIVE PROCESS
}

\author{
SMARTPHONES PARA USO EN LA PRÁCTICA EDUCATIVA: \\ EXPERIENCIA Y PROCESO CREATIVO
}

Alexandre Gasparotti Nunes

\begin{abstract}
RESUMO
Apresento neste artigo algumas considerações sobre uma experiência em que os smartphones foram usados não como ferramenta didática para o ensino de conteúdos escolares. Ao longo do processo de desenvolvimento da minha pesquisa de mestrado em que analisei as possibilidades de uso dos smartphones em situações escolares de aprendizagem me deparei com outra perspectiva para pensar o uso das novas tecnologias da informação e os seus dispositivos móveis de comunicação em práticas educativas. Essa perspectiva se refere não a maneiras de usar esses dispositivos para tarefas que visam à aprendizagem, mas ao emprego dos seus recursos em experiências educativas que se constituem como processos de criação. Com base em Leite (2011), considero que as formas de desenvolver as práticas educativas devem ir além da concepção de trabalho estritamente didático e técnico, constituindo de outra maneira espaços possíveis onde emergem experiências educativas. Entendo, portanto que é preciso analisar se os smartphones podem ser considerados potentes instrumentos para a realização de práticas educativas nas quais a criação pode se efetivar como produção maquínica (GUATTARI, 1996). Essa análise deve ser efetivada observando como nas intersecções da máquina social (a escola) com as máquinas técnicas (smartphones) pode ocorrer o alargamento das possibilidades de criação. A experimentação nas práticas educativas deve, portanto, ir muito além da mera possibilidade de encontrar novas maneiras de ensinar conteúdos.
\end{abstract}

PALAVRAS-CHAVE: Smartphones. Experiências educativas. Processo criativo.

\begin{abstract}
I present in this article some thoughts about an experience that smartphones were not used as a teaching tool for teaching school subjects. Throughout the development process of my masters dissertation that analyzed the use of smartphones possibilities in school learning situations I came across another perspective to consider the use of new information technologies and their mobile communication devices in educational practices. This perspective refers not to ways to use these devices for tasks aimed at learning, but the use of its resources on educational experiences that are creative processes. Based on Leite (2011), consider the ways to develop educational practices should go beyond the strictly educational and technical work designing, making otherwise possible spaces where emerging educational experiences. I therefore consider that it is necessary to examine whether smartphones can be considered powerful tools for the implementation of educational practices in which creation can be effective as machinic production (GUATTARI, 1996). This analysis should be carried out observing how the intersections of the social machine (school) with technical equipment (smartphones) can occur extending the possibilities of creation. Experimentation in educational practices will, therefore, beyond the mere possibility of finding new ways of teaching contente.
\end{abstract}

KEYWORDS: Smartphones. Educational experiences. Creative process. 


\section{RESUMEN}

Que presento en este artículo algunas reflexiones sobre una experiencia que los teléfonos inteligentes no fueron utilizados como una herramienta de enseñanza para las materias escolares de enseñanza. A lo largo del proceso de desarrollo de mi disertación de maestría que analisa el uso de las posibilidades de los teléfonos inteligentes en situaciones de aprendizaje de la escuela me encontré con otra perspectiva para considerar el uso de las nuevas tecnologías de la información y sus dispositivos de comunicación móvil en las prácticas educativas. Esta perspectiva no se refiere a formas de utilizar estos dispositivos para tareas dirigidas al aprendizaje, pero el uso de sus recursos en las experiencias educativas que son procesos creativos. Basado em Leite (2011), considerar las formas de desarrollar prácticas educativas deben ir más allá del diseño de trabajo estrictamente educativo y técnico, por lo que de otro modo posibles espacios donde emerge experiencias educativas. En consecuencia, considero que es necesario examinar si los teléfonos inteligentes pueden ser considerados potentes herramientas para la implementación de las prácticas educativas en el que la creación puede ser eficaz como la producción maquínica (GUATTARI, 1996). Este análisis se debe llevar a cabo la observación de cómo se pueden producir las intersecciones de la máquina social (escuela) con el equipo técnico (teléfonos inteligentes) que se amplían las posibilidades de creación. La experimentación en las prácticas educativas será, por lo tanto, más allá de la mera posibilidad de encontrar nuevas formas de contenido de la enseñanza.

PALABRAS CLAVE: Teléfonos inteligentes. Experiencias educativas. Proceso creativo.

\section{MAPEAMENTO DE UMA CAMINHADA COM O USO DE SMARTPHONES: PLANEJAMENTO DE UMA EXPERIÊNCIA DE PESQUISA}

Ao longo do processo de desenvolvimento da minha dissertação de mestrado ${ }^{1}$ em que analisei as possibilidades de uso dos smartphones em práticas educativas, elaborei uma atividade cuja finalidade era experimentar o uso do smartphone como ferramenta de mapeamento. Essa atividade foi efetuada durante o mês de maio do ano de 2014, e dela participou um grupo heterogêneo (idade, sexo e ano escolar) de alunos de uma escola pública de ensino fundamental do terceiro e quarto ciclos, localizada na cidade de Bauru-SP. A referida atividade constituía o processo de produção de dados da pesquisa. Segundo Kastrup (2014) há dois tipos de perspectivas políticas de produção do conhecimento: a realista e a construtivista. Na linha da perspectiva realista, o mundo oferece informações prontas para serem apreendidas. Por outro lado, na perspectiva construtivista o pesquisador deve tomar o mundo como uma invenção engendrada conjuntamente com os agentes do conhecimento. Portanto, a atividade de pesquisa que aqui apresento foi desenvolvida dentro dessa segunda perspectiva de produção do conhecimento, e nesse sentido ela pode ser considerada um processo de produção de dados.

Antes da realização da atividade com os alunos, efetuei um levantamento bibliográfico sobre experiências de uso do smartphone em atividades escolares de ensino de cartografia geográfica. Após uma busca exaustiva por estudos sobre esse tema descobri que há pouco interesse dos pesquisadores em educação e ensino da geografia pelo tema do uso do smartphone em atividades de ensino de cartografia, haja visto a escassez de textos sobre a

\footnotetext{
${ }^{1}$ A referida dissertação, intitulada $\mathbf{O}$ uso do smartphone em atividades educativas: considerações a partir de uma experiência com alunos do ensino fundamental, foi desenvolvida junto ao Programa de PósGraduação (Mestrado Acadêmico) em Estudos Culturais da Escola de Artes, Ciências e Humanidades da Universidade de São Paulo (EACH/USP), sob a orientação da Profa. Dra. Valéria Cazetta.
} 
temática em questão. Mas por outro lado encontrei alguns estudos que apresentam projetos artísticos criados no ambiente virtual da web $2.0^{2}$ que exploram a tecnologia Global Positioning System (Sistema de Posicionamento Global). Segundo Machado (2012) o GPS, ou Global Positioning System (Sistema de Posicionamento Global), é uma rede de satélites integrada a outros dispositivos que presta informações precisas sobre o posicionamento individual no globo terrestre. Esse sistema funciona desde 1995, tendo sido criado pelo Departamento Americano de Defesa para fins militares. Hoje é amplamente aproveitado pelo setor civil, principalmente pela aviação comercial. De modo geral, a arquitetura desse sistema consiste em uma constelação de 24 satélites, que funciona como elemento principal do aparato, enviando informações para que qualquer dispositivo receptor calcule a posição do usuário.

Em cada um desses projetos usa-se o GPS incorporado nos aparelhos de smartphone para criar intervenções artística no espaço urbano que convidam a pensar sobre possíveis efeitos negativos da confiança excessiva dos usuários desses aparelhos quanto à precisão destes para encontrar endereços e fornecer rotas de tráfego para motoristas e pedestres. Dentre esses efeitos, destacam-se a atrofia das imaginações espaciais (BEIGUELMAN, 2012) e a condição de verdade e realidade dos mapas gerados pelo GPS. Assim, ao promoverem intervenções no espaço urbano que visam à crítica do mapeamento com o GPS, esses projetos artísticos podem ser considerados atividades com potencial educativo porque permitem, no que concerne à cartografia, pensar sobre os limites da eficiência do mapeamento produzido através do GPS.

Elaborei, então, uma atividade de mapeamento semelhante a um dos projetos artísticos descritos por Lemos (2007). O projeto que inspirou minha atividade chama-se: Mobotag: Conectando sua cidade com marcadores móveis. Este consistiu na construção de um sítio na internet no qual havia um mapa eletrônico da cidade de Nova Iorque onde eram inseridas automaticamente informações de e-mails com arquivos de fotos, textos, vídeos, ou de sons da cidade, geradas a partir de qualquer local com o uso de um smartphone. Assim, após o envio do e-mail pelos participantes, o sistema eletrônico do sítio do projeto adicionava automaticamente as informações aos pontos do mapa da cidade em questão. Esse tipo de uso do GPS que permite marcar elementos encontrados durante uma caminhada pela cidade é considerado por Leirias (2012, p. 122) uma atividade artística muito parecida com a intervenção no espaço urbano chamada de deriva, criada pela Internacional Situacionista ${ }^{3}$. Segundo a autora, a deriva insere-se numa modalidade de prática experimental de exploração

\footnotetext{
${ }^{2}$ Bassani, Barbosa e Patrícia (2013) explicam que web 2.0 é a nomenclatura dada à nova arquitetura operacional da internet, a qual criou a possibilidade daquilo que se convencionou denominar de ciberespaço. A característica mais importante dessa nova arquitetura é a possibilidade que ela criou de interação constante entre muitas pessoas, permitindo a conexão de múltiplos dispositivos e a construção coletiva da informação acessada nos espaços da rede como blogs, redes sociais, etc.

3 Internacional Situacionista foi um movimento artístico e político influenciado pelas escolas artísticas denominadas dadaísmo e surrealismo. O movimento situacionista remonta a 1957 e seu maior expoente foi o escritor francês Guy Debord. O movimento situacionista pretendia superar a noção de arte como obra de gênios da humanidade, buscando em cada momento e atitudes da vida cotidiana uma expressão da arte.
} 
da cidade e do meio ambiente urbano que permite apreender objetos não contemplados pelos mapas produzidos pelo GPS. Assim, uma caminhada pela cidade percorrendo um trajeto não planejado pode revelar aspectos e elementos invisíveis da morfologia social sob a óptica do mapeamento produzido pelo GPS. Nas palavras da autora supracitada:

Quando se pensa em cartografia nas artes visuais, as estratégias situacionistas são referências vitais para se pensar uma relação crítica e singular com o espaço, com as instituições e com o cotidiano. Problematizam a cidade, o urbano, a arquitetura, a vida cotidiana, e constituem práticas coletivas de criação artística como exercício de novos modos de experienciar os espaços urbanos.

Defini então, inicialmente, a estratégia de reunir os alunos e produzir um mapa no sítio do Google no qual seriam marcados por meio de "fotografias" ${ }^{4}$ " os pontos em que se localizavam os objetos encontrados no percurso de uma caminhada pelas ruas de um bairro da cidade de Bauru-SP. O processo de produção desse mapa consistiria, num primeiro momento, em fotografar com o smartphone os objetos e anexar essas "fotografias" nos pontos do mapa do Google correspondentes à localização de cada objeto. Além da câmera do smartphone, esse registro deveria ser feito com o aplicativo Whatsapp, da seguinte maneira:

a) Cada participante encontra e fotografa um objeto em determinado ponto do percurso; em seguida, edita a "fotografia" com um aplicativo de livre escolha, e compartilha a "fotografia" num grupo de chat (ambiente virtual) por mim criado no aplicativo Whatsapp especificamente para essa atividade.

b) Depois de editar e compartilhar a "fotografia", o participante compartilha um mapa com a indicação do ponto do terreno em que o objeto estava situado. Nesse mapa, um símbolo semelhante a um pingo d'água indica o ponto exato do terreno em que o participante obteve a fotografia, como mostram as figuras abaixo. Esse procedimento é muito simples: basta que o participante se aproxime do objeto e acione a ferramenta localização, presente na parte inferior da tela de interface do aplicativo Whatsapp.

c) Por fim, na última etapa eu me reuniria com os alunos num local onde houvesse disponibilidade de computadores com acesso à internet para que cada um postasse as suas fotografias num blog de minha autoria. Após a postagem das suas fotografias no blog, cada participante efetuaria o procedimento de anexar a "fotografia" no mapa.

\footnotetext{
${ }^{4}$ Imagens fotográficas oriundas de smartphones e câmeras digitais não são propriamente grafias de luz no plano do negativo, como é o caso da técnica original da criação da fotografia. Portanto, se obtêm com os smartphones e câmeras digitais é uma imagem numérica produzida a partir de uma linguagem binária pixelizada. Por isso as aspas nesta palavra.
} 


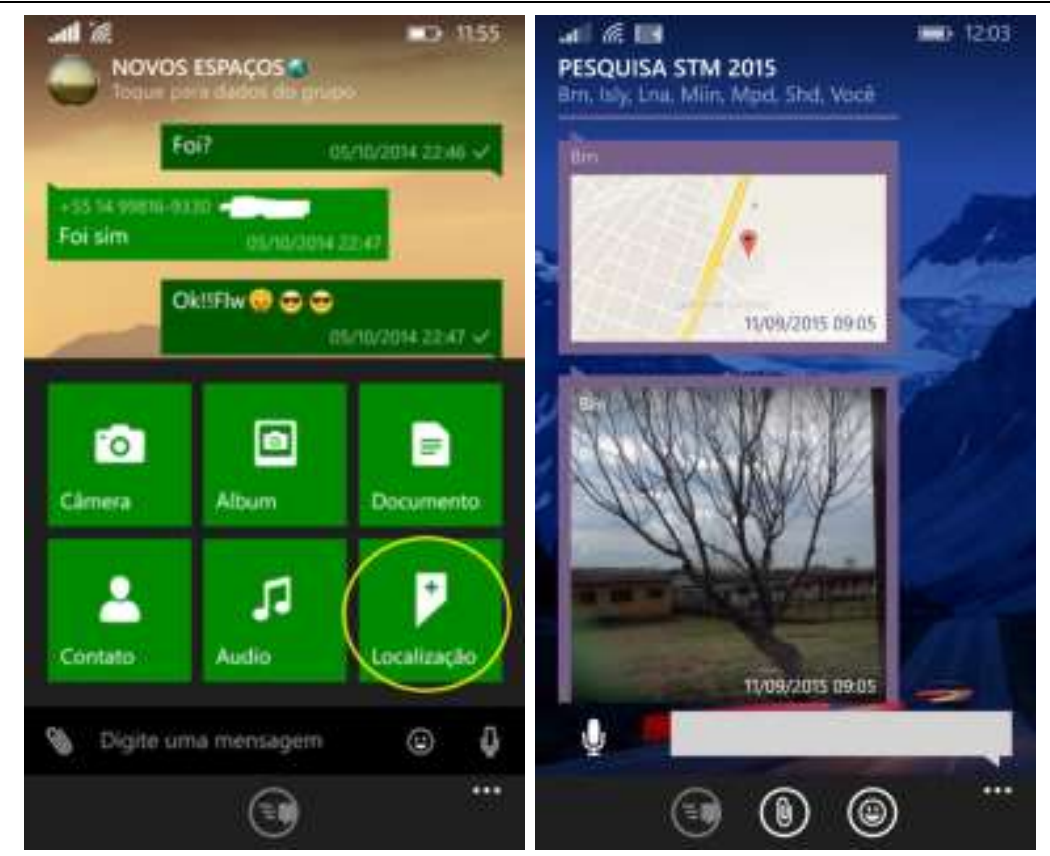

FIGURAS 1 e 2 - Funcionamento da ferramenta de localização do Whatsapp Fonte: pesquisa de campo

Programei uma sequência de três encontros com o grupo, totalizando uma carga horária de seis horas aula. Meu planejamento inicial era destinar os dois primeiros encontros para me apresentar aos alunos, explicar os procedimentos da atividade e exercita-los no espaço da escola. O terceiro dia ficaria reservado para nos deslocarmos até a área da cidade de Bauru-SP, por mim escolhida, e efetuarmos a caminhada e o registro dos objetos conforme os procedimentos explicados e praticados nos dois primeiros encontros. Após a caminhada, nos reuniríamos na escola para fazer a marcação das fotos no mapa do sítio do Google.

\section{CONSIDERAÇÕES SOBRE A EXPERIÊNCIA}

Quando estava planejando as atividades desta pesquisa, eu imaginava que não haveria problema algum em realizar essas atividades numa escola de ensino fundamental ou médio. Mas quando eu entrei em contato com a direção de algumas escolas a fím de expor as características da pesquisa e, principalmente, solicitar consentimento para a efetuação das atividades com a participação de alunos, recebi respostas negativas ou imposição de condições que alterariam muito o arcabouço do trabalho. Recorri então a uma escola pública de ensino fundamental da cidade de Bauru-SP onde eu já havia lecionado. Nessa escola alguns professores e a diretora já me conheciam, e isso me ajudou a obter autorização para a realização da atividade. Infelizmente a escola não possuía uma sala de aula com computadores conectados na internet especificamente destinada para o desenvolvimento de atividades de ensino. Dessa maneira, sem ter esse tipo de espaço à disposição, tornou-se inviável efetuar a reunião com os alunos, logo após a caminhada, para fazer a anexação das fotografias ao mapa do sítio do Google. 
Durante os dois primeiros dias, a atividade consistiu na prática de um exercício sobre a maneira de usar o GPS para marcar os pontos do percurso de uma caminhada. Chamou minha atenção o procedimento efetuado pelos três participantes mais engajados no exercício. Um primeiro deles possuía o smartphone modelo Samsung Galaxy Gran Duos, e usava o aplicativo chamado Rétrica para efetuar a edição das "fotografias". Esse participante me contou que o aplicativo em questão permite alterar aspectos da "fotografia" original como a cor e a forma da imagem, além de permitir também edita-la em múltiplos quadros e repetir automaticamente a mesma "fotografia" sucessivamente.
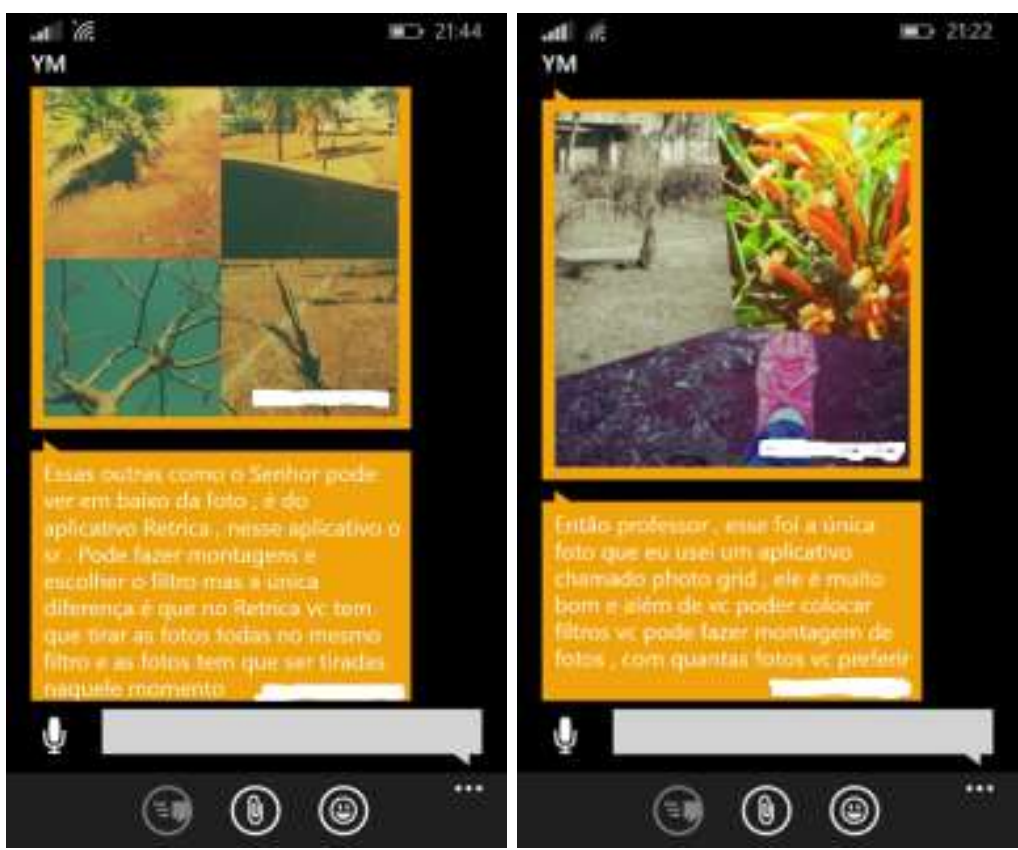

FIGURAS 3 e 4 - Fotos editadas com o aplicativo Rétrica Fonte: pesquisa de campo

Um segundo participante possuía o smartphone Nokia Lumia 520. Ele utilizou o aplicativo chamado Editor de Fotos para montar suas "fotografias". Esse aplicativo também permitiu cortar, redimensionar e alterar o formato da imagem, combinar efeitos como o matiz e saturação das cores da imagem. Por fim, um terceiro participante dentre os mais engajados possuía o smartphone iPhone $4 \mathrm{~S}$, e utilizou dois aplicativos desse smartphone para editar suas "fotografias". Tratam-se dos aplicativos MegaPhoto e PhotoMirror. Com o aplicativo PhotoMirror esse participante conseguiu inverter a ordem real dos referentes da imagem "fotográfica" tal qual ocorre com qualquer objeto colocado diante de um espelho. 


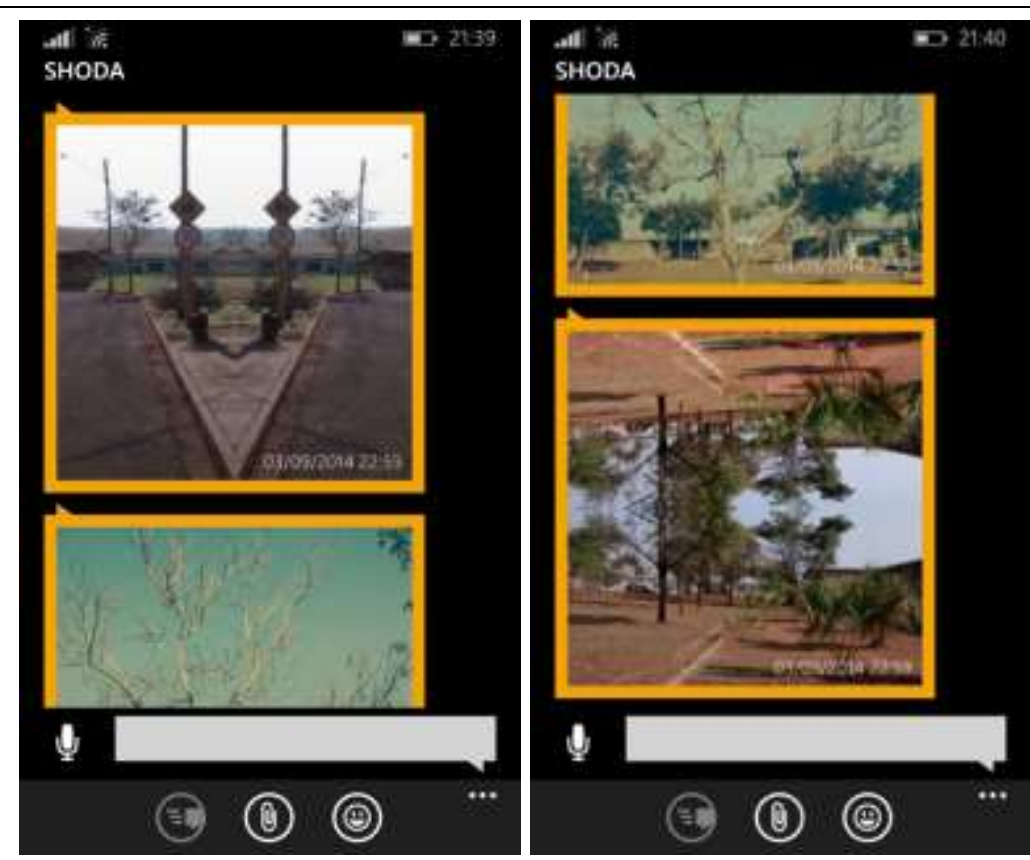

FIGURAS 5 e 6 - Fotos editadas com o aplicativo PhotoMirror Fonte: pesquisa de campo

No dia da caminhada, embora a atividade oferecesse a oportunidade de usar espontaneamente os aplicativos de GPS e de edição de fotografias do smartphone, os participantes mais engajados na atividade faziam tudo mecanicamente, ou seja, eles apenas repetiam os procedimentos dos exercícios demonstrativos praticados na escola nos dois encontros anteriores. Essas observações me fizeram conjecturar que embora as tecnologias infocomunicacionais do smartphone e a dinâmica artística da atividade abrissem espaço para um processo de criação, aqueles jovens ainda agiam como se estivessem submetidos às mesmas normas de conduta e relações de saber-poder típicas da cultura escolar.

\begin{abstract}
Para ser breve, poder-se-ia descrever a cultura escolar como um conjunto de normas que definem conhecimentos a ensinar e condutas a inculcar, e um conjunto de práticas que permitem a transmissão desses conhecimentos e a incorporação desses comportamentos; normas e práticas coordenadas a finalidades que podem variar segundo as épocas (finalidades religiosas, sociopolíticas ou simplesmente de socialização). (JULIA, 2001, p. 10, itálico do autor)
\end{abstract}

Dessa maneira, cotejando essas observações com o conceito de governamentalidade elaborado por Foucault (2008) é possível inferir que as relações de saber-poder escolares influenciaram o comportamento e o modo de pensar dos participantes da pesquisa mesmo à distância do meio ambiente escolar, despotencializando o espaço de criação e experimentação que a atividade procurou constituir. Segundo o filósofo supracitado, as instituições cuja função é ordenar e conduzir grandes contingentes humanos, tais como a escola, definem previamente normas de conduta que limitam a dinâmica das ações daqueles que ali se encontram e, por conseguinte, as experiências possíveis para estes sujeitos. Essa característica das instituições promoveu o desenvolvimento histórico de estratégias que respondessem aos desafios de cada período para a arte de governar, dentre eles o estabelecimento de um critério 
de verdade para os ditames das práticas de condução dos sujeitos envolvidos nas relações de saber-poder dentro das instituições.

Tendo isso em vista é possível afirmar que a escola contemporânea coloca em vigor suas relações de saber-poder de acordo com o princípio da governamentalidade. Com o conceito de governamentalidade, Foucault (2008) se refere a um complexo constituído por instituições, técnicas de exercício do poder, um conjunto de saberes e também dispositivos criados com o objetivo de gerir contingentes populacionais. Efetivamente, na história do ocidente emergiu desde o século XVIII um tipo de saber, o chamado saber de governo, o qual paulatinamente adquiriu proeminência sobre saberes e técnicas tais quais a disciplinaridade, criada em paralelo ao desenvolvimento de práticas institucionais de condução dos indivíduos. Contudo, mesmo que o fulgor dos processos contemporâneos de governamentalidade permita formular interpretações de que os saberes e técnicas disciplinares estão em declínio, principalmente nas instituições escolares, o mais correto seria pensar que houve sim um refinamento " [...] das técnicas e tecnologias de poder, cuja testemunha mais viva e eficaz são as artes de governo" (CARVALHO, 2014, p. 115).

Nesse sentido, a noção de governamentalidade abarca todo o conjunto de práticas de condução que um sujeito pode, concomitantemente, aplicar sobre os outros e sobre si mesmo nas esferas macrossociais e microssociais. Para Veiga Neto (2008) essas práticas podem ser efetuadas tanto sobre a esfera material do corpo, quanto sobre a esfera psíquica dos sujeitos, com o apoio de técnicas específicas e refinadas que numa perspectiva foucaultiana podem ser consideradas como técnicas de dominação e de poder, caso sejam efetuadas de um sujeito ou grupo de sujeitos sobre outros, ou como tecnologias do eu, caso sejam efetuadas pelo próprio sujeito sobre si mesmo. Nas análises desenvolvidas em Vigiar e Punir sobre o exercício das relações de saber-poder nas instituições disciplinares, as observações de Foucault (2013) sobre a acurácia dos dispositivos de vigilância, tais como o panóptico, e dos instrumentos de sancionamento e classificação dos indivíduos, tais como o exame escolar, demonstram que essas relações não se efetivaram como um tipo de violência, pois a violência implica um exercício tão brutal do poder que acaba anulando o movimento e das forças daqueles que se encontram no polo dominado da relação de poder. Ao contrário, nas relações de saber-poder ocorre um chamamento dos sujeitos a aderirem docilmente a determinados trabalhos, maximizando assim a capacidade produtiva dos seus corpos. Essa característica do poder disciplinar Foucault chama de positividade (VEIGA-NETO, 2008).

Com efeito, a escola moderna se constituiu numa máquina de produção de sujeitos adequadamente moldados para o tipo de vida requerido pela ordem social capitalista. Essa máquina ficou encarregada de produzir sujeitos disciplinados, adaptados a determinados códigos de conduta e sempre prontos a cumprirem obrigações inerentes às suas posições na ordem social. Tendo em vista a dificuldade dos participantes desta pesquisa usarem, com independência e criatividade, todas as ferramentas do smartphone escolhidas para a atividade, faz-se necessário um questionamento também sobre o impacto da governamentalização da educação escolar sobre o potencial criativo dos alunos. Assim, se as artes de governo em vigor na educação escolar contemporânea se caracterizam por uma estratégia de domínio

\begin{tabular}{l|l|l|l|l|l|l} 
(C) ETD - Educ. Temat. Digit. & Campinas, SP & v.18 & n.4 & p. 889-902 & out./dez.2016 & ISSN 1676-2592
\end{tabular}


mais sutil que não tem mais os corpos dos alunos como objeto preferencial de aplicação de práticas de controle e condução; se a governamentalidade em vigor nas escolas contemporâneas efetua-se através da inculcação de modos pré-configurados de pensar e de agir, ao invés da coerção física e vigilância constante, produzindo assim sujeitos cientes do lugar que devem ocupar e daquilo que devem fazer, penso que esse processo pode se constituir numa obstáculo para o desenvolvimento da criação nas práticas educativas.

De outro modo, o que percebi após a o desenvolvimento da experiência desta pesquisa é que a potência criativa de uma atividade depende do agenciamento de processos de singularização, isto é, da reapropriação pelos indivíduos dos elementos materiais e semióticos do processo de criação, subvertendo-os em formas de uso diferentes do comum. Segundo Guattari (1996, p. 55):

\begin{abstract}
Um processo de singularização da subjetividade pode ganhar uma imensa importância, exatamente como um grande poeta, um grande músico ou um grande pintor que, com suas visões singulares da escrita, da música ou da pintura, podem desencadear uma mutação nos sistemas coletivos de escuta e de visão.
\end{abstract}

Entendo, portanto, que a experiência desta pesquisa, assim como qualquer outro tipo de experiência educacional, para ter se efetivado como uma atividade criativa precisaria ter sido capaz de agenciar esses processos de singularização. Na próxima secção procuro desenvolver mais essa consideração.

\title{
3 EXPERIÊNCIA EDUCATIVA E PROCESSOS DE SINGULARIZAÇÃO
}

Nas sociedades capitalistas, os vetores da produção da subjetividade se encontram em âmbitos espaciais muito mais amplos do que o círculo familiar ou as instituições estatais. $\mathrm{O}$ processo de produção da subjetividade nessas sociedades é diferente dos processos de subjetivação territorializados em sistemas de organização social como as tribos, os clãs, etc. Nesse sentido, a produção da subjetividade no capitalismo se assemelha a um processo de manufatura de mercadorias industrializadas, como em um processo em que múltiplos vetores (meios de comunicação de massa, família, instituições do Estado, empresas, etc.) externos agem simultaneamente na formatação de desejos, valores, hábitos e modos de vida.

A resistência política a esses processos de subjetivação nos diversos âmbitos da vida social também pode ser considerada como parte de processos de singularização. Segundo Guattari (1996) os processos de singularização são resultado do autoposicionamento político de grupos que se recusam a repetir os padrões de comportamento e de pensamento preestabelecidos pelas instituições ou pelos poderes sociais, buscando assim constituir “[...] de certa forma, modos de sensibilidade, modos de relação com o outro, [...] modos de criatividade que produzam uma subjetividade singular” (GUATTARI, 1996, p. 17). 
De outra maneira, a experiência educativa pode ser considerada, se tomarmos em consideração a perspectiva do autor supracitado, um processo de singularização quando as linguagens, as técnicas de ensino e materiais pedagógicos, inclusive as novas tecnologias da informação e comunicação, são reutilizados pelos sujeitos da experiência através da suspensão das formas de uso consagradas pelo discurso das ciências da educação. Numa perspectiva filosófica semelhante, Agamben (2007, p. 67) considera como profanação a capacidade que as crianças têm de transformar qualquer objeto em brinquedo através suspensão dos seus usos comuns. Nas palavras do filósofo italiano:

As crianças, que brincam com qualquer bugiganga que lhes caia nas mãos,
transformam em brinquedo também o que pertence à esfera da economia, da guerra,
do direito e das outras atividades que estamos acostumados a considerar sérias. Um
automóvel, uma arma de fogo, um contrato jurídico transformam-se
improvisadamente em brinquedos.

A profanação permite pensar a experiência educativa enquanto montagem. Nesse sentido, considero que a montagem, tal como apresentada por Brasil (2004) é compatível com a prática da experiência educativa nas atividades escolares com o uso das novas tecnologias da informação e comunicação, inclusive os smartphones, porque essa atividade criativa consiste em suspender do uso comum dos aparatos tecnológicos e seus recursos infocomunicacionais (computadores, aparelhos de rádio, de TV, e o próprio smartphone). "A profanação da montagem [e pela montagem] aproximaria a linguagem da experiência e nos levaria de volta ao processo de criação" (LEITE, 2011, p. 150).

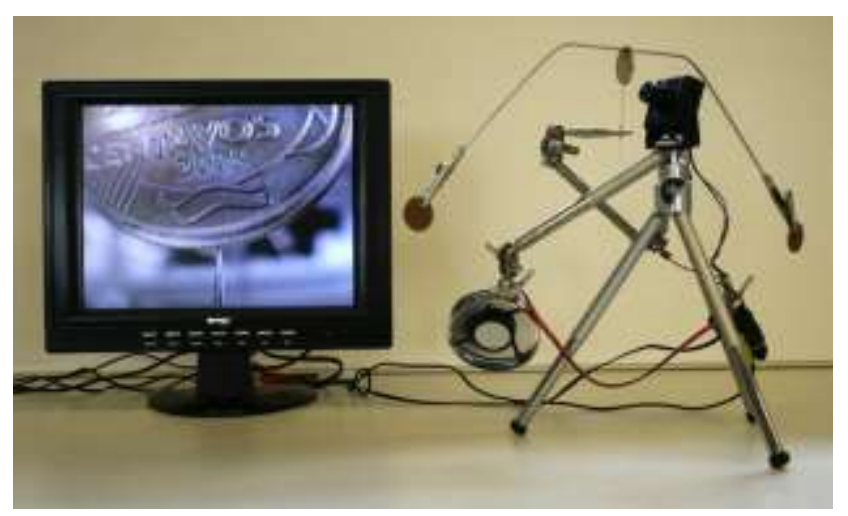

Figura 7 - Real Instável: obra de Milton Marques.

Fonte: 〈http://goo.gl/HspUwA>.

Nesse sentido, a profanação ajuda a pensar a experiência educativa com as novas tecnologias da informação e comunicação. A obra do artista Milton Marques é um exemplo disso, já que seus trabalhos artísticos consistem em desmontar e remontar aparelhos eletroeletrônicos de modo a instituir novas funções a eles, suspendendo o uso comum a eles atribuído. De acordo com Brasil (2008, p. 137):

As obras de Milton Marques expõem uma espécie de infância, de memória da tecnologia e, ao mesmo tempo, seu inacabamento, seu estado de potência. Deixam claro também que essa potência reside na dimensão de uso, de apropriação. Essa é uma experiência com o dispositivo e com a linguagem: uma montagem. Ela expõe o dispositivo e a linguagem como medialidades. 
Para Masschelein (2013) o uso dessas tecnologias nas práticas escolares não pode ser restrito à busca de ganhos de aprendizagem, pois isso anularia toda a potência dessas tecnologias para produzir experiências educativas. À luz do conceito de profanação, pode-se dizer que a possibilidade da experiência educativa reside na ação subverter o uso convencional dos objetos ou materiais pedagógicos. Assim sendo, produzir experiência na educação escolar é profanar e singularizar o modo de uso dos materiais disponíveis para as atividades pedagógicas. Assim, a experiência educativa se efetiva quando alguma coisa pertencente ao mundo é oferecida para um uso livre e inusitado. Isso ocorre na medida em que a escola permite criar situações em que as coisas do mundo são postas para serem usadas da mesma maneira que a criança faz quando transforma um objeto qualquer em peça de um jogo. Entretanto, penso que a governamentalização da educação escolar interdita a possibilidade da experiência educativa da maneira como afirma Masschelein (2013). Posto isso, penso que o uso das novas tecnologias da informação e comunicação apenas como ferramenta didática de ensino das disciplinas escolares não é compatível com a produção de experiências educativas na educação escolar.

\section{CONSIDERAÇÕES FINAIS}

A característica primordial da escola da polis ateniense era a suspensão, isto é, a transformação do tempo escolar em tempo livre. O sentido das práticas escolares é a transformação do tempo escolar em tempo improdutivo não no sentido de ociosidade, mas de momento em que se tem o direito de usufruir um tempo em que não se deve obrigatoriamente produzir tal qual no mundo do trabalho fora da escola. Em linhas gerais a escola grega estabeleceu um tempo e espaço que estava separado do tempo e espaço tanto da sociedade e da família (MASSCHELEIN, 2013).

Entretanto, em virtude das transformações econômicas e políticas da modernidade, o discurso pedagógico passa a propor o enfoque do processo educativo na aquisição de competências e habilidades. Isso favoreceu a transformação da rotina escolar numa convocação incessante à ocupação dos corpos e mentes dos alunos com atividades cujo objetivo é contribuir com a aprendizagem. Dessa maneira, a palavra aprendizagem tem se convertido, em muitas ocasiões da rotina escolar, numa espécie de mantra pseudopedagógico para a imposição de uma hipertrofia do tempo em que os alunos são obrigados a manterem seus corpos e mentes sempre ocupados e produzindo, seja com atividades relativas ao conteúdo das disciplinas escolares, seja com atividades que estimulam atitudes de autodisciplinamento. Em contraposição a esse modelo, o autor supracitado apresenta a proposta de uma escola enquanto local do tempo livre para o cultivo de saberes e técnicas. A essa proposta o autor deu o nome de escola experimental.

A proposta de escola experimental é um contraponto à política educacional que concebe a escola como instituição cuja finalidade é prover treinamento de trabalhadores capazes de se adaptar às modificações constantes do sistema produtivo. Assim, pode-se dizer \begin{tabular}{l|l|l|l|l|l|l} 
(C) ETD - Educ. Temat. Digit. & Campinas, SP & v.18 & n.4 & p. 889-902 & out./dez.2016 & ISSN 1676-2592
\end{tabular} 
que a meta das políticas educacionais da era capitalista da globalização é transformar a população de um país em mão de obra empregável. Essas reformas educacionais contribuem para a disseminação de exortações frequentes aos profissionais da educação em exercício nas escolas de educação básica para que tenham foco total na eliminação de déficits de aprendizagem de determinados alunos, geralmente aqueles que apresentam os piores resultados de aprendizagem, isto é, notas baixas nas provas ou avaliações.

O desafio da escola experimental proposta por Masschelein (2013) não é o de empreender um retorno às antigas práticas e técnicas escolares de um passado no qual a escola se caracterizava pelo excessivo rigor disciplinar tanto em relação às normas de comportamento quanto aos rituais e técnicas de ensino e avaliação do rendimento dos alunos nas respectivas disciplinas escolares. É nesse sentido que as novas tecnologias da informação e comunicação oferecem oportunidades para a realização de experiências educativas cuja finalidade é a criação deste tempo livre para o cultivo do conhecimento coligido nas disciplinas escolares que congregam os saberes científicos, filosóficos, artísticos. O problema das práticas educativas escolares no que tange a uma formação tecnológica é que os recursos comunicacionais e informacionais dos artefatos têm sido convertidos em ferramentas cuja potência reside na produção de resultados específicos de aprendizagem.

\section{REFERÊNCIAS}

AGAMBEN, Giorgio. Profanações. São Paulo: Boitempo, 2007. Disponível em: <http://goo.gl/invSGB >. Acesso em: 30 ago. 2016.

BASSANI, Patrícia Brandalise Scherer; BARBOSA, Débora Nice Ferrari; ELTZ, Patrícia Thoma. Práticas pedagógicas com a web 2.0 no ensino fundamental. Espaço Pedagógico, Passo Fundo, RS, v. 20, n. 2, p. 286-300. jul./dez. 2013. Disponível em: <http://goo.gl/F3Il3V > . Acesso em: 15 de dez. 2013. ISSN 2238-0302.

BEIGUELMAN, Giselle. Mapas diagramáticos como dispositivos críticos da hiperlocatividade. V!RUS, São Carlos, SP, n. 08. dez. 2012. Disponível em: <http://goo.gl/dmnlNZ>. Acesso em: 10 de jun. 2014. ISSN 2175-974X.

BRASIL. André Guimarães. Modulação e montagem: ensaio sobre biopolítica e experiência estética. 2004. 206 f. Tese - (Doutorado em Comunicação e Cultura Contemporânea). Escola de Comunicação, Universidade Federal do Rio de Janeiro, Rio de Janeiro, RJ, 2004.

Disponível em: 〈http://goo.gl/5KMq9O >. Acesso em: 30 ago. 2016.

CARVALHO, Alexandre Filordi de. Foucault e a crítica às instituições da educação: implicações para as artes de governo. Pro-posições, Campinas, SP, v. 25, n. 02, p. 103-120. mai./ago. 2014. Disponível em: 〈http://goo.gl/CP5Vos〉. Acesso em: 30 ago. 2016. ISSN $1980-6248$. 
FOUCAULT, Michel. Segurança, território, população: curso dado no Collège de France (1977-1978). São Paulo: Martins Fontes, 2008. Disponível em: 〈http://goo.g1/V3A5eF〉. Acesso em: 30 ago. 2016.

FOUCAULT, Michel. Vigiar e punir: nascimento da prisão. Petrópolis: Vozes, 2013. Disponível em: 〈http://goo.gl/5tPPae $>$. Acesso em: 30 ago. 2016.

GUATTARI, Félix; ROLNIK, Suely. Cartografias do desejo. Petrópolis: Vozes, 1996. Disponível em: 〈http://goo.gl/1Xsr9I >. Acesso em: 30 ago. 2016.

JULIA, Dominique. A cultura escolar como objeto histórico. Revista Brasileira de História da Educação, Campinas, SP, n. 01, p. 09-43. jan./jun. 2001. Disponível em: <http://goo.gl/LfBvQV>. Acesso em: 30 ago. 2016. ISSN 2238-0094.

KASTRUP, Virgínia. O funcionamento da atenção no trabalho do cartógrafo. In: PASSOS, Eduardo; KASTRUP, Virgínia; ESCÓSSIA, Liliana da. (Orgs). Pistas do método da cartografia: intervenção e produção de subjetividade. Porto Alegre: Sulina, 2009. p. 32-51. Disponível em: 〈http://goo.gl/t6muUa $>$. Acesso em: 30 ago. 2016.

LEITE, César Donizetti Pereira. Infância, experiência e tempo. São Paulo: Cultura Acadêmica, 2011. 169 p. Disponível em: 〈http://goo.gl/qoy50W〉. Acesso em: 30 ago. 2016.

LEIRIAS, Ana Gabriela. Novas cartografias online, arte contemporânea e outras geografias. Geograficidade, Niterói, RJ, v. 02, n. especial. 2012. Disponível em: <http://goo.gl/JShwYw>. Acesso em: 30 ago. 2016. ISSN 2238-0205.

LEMOS, André. Comunicação e práticas sociais no espaço urbano: as características dos dispositivos híbridos móveis de comunicação multirredes (DHMCM). Comunicação, Mídia e Consumo, São Paulo, SP, v. 04, n. 10, p. 23-40. jul. 2007. Disponível em: <http://goo.gl/FV5Fnn>. Acesso em: 30 ago. 2016. ISSN 1983-7070.

MACHADO, Jonathan. O que é GPS?. Disponível em: 〈http://goo.gl/wzw44>. Acesso em: 22 jun. 2016.

MASSCHELEIN, Jan; SIMONS, Maarten. Em defesa da escola: uma questão pública. Belo Horizonte: Autêntica, 2013.

VEIGA-NETO, Alfredo. Dominação, violência, poder e educação escolar em tempos de império. In: RAGO, Margareth; VEIGA-NETO, Alfredo. (Orgs.). Figuras de Foucault. Belo Horizonte: Autêntica, 2008. 
ALEXANDRE GASPAROTTI NUNES

Professor de Geografia

Escola Municipal de Ensino Fundamental

"Ivan Engler de Almeida" - Bauru - SP

E-mail: alex78gn@gmail.com

Recebido em: 30/08/2016

Aprovado para publicação em: 09/10/2016

Como citar este documento:

NUNES, Alexandre Gasparotti. Uso de smartphones na prática educativa: experiência e processo criativo. ETD - Educação Temática Digital, Campinas, SP, v. 18, n. 4, p. 889-902, nov. 2016. ISSN 1676-2592. Disponível em: 〈http://periodicos.sbu.unicamp.br/ojs/index.php/etd/article/view/8646411 >. Acesso em: 16 nov. 2016. doi:http://dx.doi.org/10.20396/etd.v18i4.8646411. 